\title{
Development of an imaging-guided CEA-pretargeted radionuclide treatment of advanced colorectal cancer: first clinical results
}

\author{
R Schoffelen ${ }^{1}$, O C Boerman ${ }^{*}, 1$, D M Goldenberg ${ }^{2,3}$, R M Sharkey ${ }^{3}$, C M L van Herpen ${ }^{1}$, G M Franssen ${ }^{1}$, \\ W J McBride ${ }^{3}$, C-H Chang ${ }^{3}$, E A Rossi ${ }^{3}$, W T A van der Graaf ${ }^{1}$ and W J G Oyen ${ }^{1}$ \\ ${ }^{1}$ Radboud University Nijmegen Medical Centre, PO Box 9101, Nijmegen, The Netherlands; ${ }^{2}$ Garden State Cancer Center, Center \\ for Molecular Medicine and Immunology, Morris Plains, NJ, USA and ${ }^{3}$ Immunomedics, Inc., Morris Plains, NJ, USA
}

Background: Radiolabelled antibody targeting of cancer is limited by slow blood clearance. Pretargeting with a non-radiolabelled bispecific monoclonal antibody (bsMAb) followed by a rapidly clearing radiolabelled hapten peptide improves tumour localisation. The primary goals of this first pretargeting study in patients with the anti-CEACAM5 $\times$ anti-hapten (HSG) bsMAb, TF2, and the radiolabelled hapten-peptide, IMP288, were to assess optimal pretargeting conditions and safety in patients with metastatic colorectal cancer (CRC).

Methods: Different dose schedules were studied in four cohorts of five patients: (1) shortening the interval between the bsMAb and peptide administration (5 days vs 1 day), (2) escalating the TF2 dose (from 75 to $150 \mathrm{mg}$ ), and (3) reducing the peptide dose (from 100 to $25 \mu \mathrm{g}$ ). After confirmation of tumour targeting by ${ }^{111}$ In-IMP288, patients were treated with a bsMAb/77 Lu-IMP288 cycle.

Results: Rapid and selective tumour targeting of the radiolabelled peptide was visualised within $1 \mathrm{~h}$, with high tumour-to-tissue ratios (> 20 at $24 \mathrm{~h}$ ). Improved tumour targeting was achieved with a 1-day interval between the administration of the bsMAb and the peptide and with the $25-\mu \mathrm{g}$ peptide dose. High ${ }^{177}$ Lu-IMP288 doses $(2.5-7.4 \mathrm{GBq}$ ) were well tolerated, with some manageable TF2 infusion reactions, and transient grades 3-4 thrombocytopaenia in 10\% of the patients who received ${ }^{177}$ Lu-IMP288.

Conclusion: This phase I study demonstrates for the first time that pretargeting with bsMAb TF2 and radiolabelled IMP288 in patients with CEA-expressing CRC is feasible and safe. With this pretargeting method, tumours are specifically and rapidly targeted.

Tumour targeting with monoclonal antibodies is an attractive approach for selective cancer therapy. For metastatic colorectal cancer (CRC), the anti-vascular growth factor receptor antibody, bevacizumab, and the anti-epidermal growth factor receptor antibodies, cetuximab or panitumumab, can improve patient outcome when combined with chemotherapy (Hurwitz et al, 2004; Giantonio et al, 2007; Amado et al, 2008; Saltz et al, 2008;
Bokemeyer et al, 2009; Tol et al, 2009; Van Cutsem et al, 2009). Antibodies conjugated with cytotoxic agents, such as drugs or radionuclides, have shown promising results in several indications (Govindan and Goldenberg, 2010; Sharkey and Goldenberg, 2011). Radiolabelled antibodies have proven effective in patients with non-Hodgkin lymphoma (Wiseman et al, 2002; Witzig et al, 2002a,b; Gordon et al, 2004), but successful 
adaptation of radioimmunotherapy (RIT) in solid tumours has been challenging (Liersch et al, 2005; Sharkey and Goldenberg, 2011).

The slow blood clearance and delayed tumour uptake of directly radiolabelled antibodies cause continuous radiation exposure to the bone marrow and a high background signal. Pretargeting techniques were developed to overcome these limitations. With pretargeting, a non-radiolabelled humanised bispecific monoclonal antibody (bsMAb) is administered first intravenously. After the bsMAb localises in the tumour and clears from the circulation, a radiolabelled hapten peptide is given that is rapidly trapped in the tumour by the bsMAb, while the remainder clears from the blood very quickly, being eliminated via the kidneys. Pretargeting reduces the radiation exposure to radiosensitive normal tissues, such as bone marrow, as well as other tissues (Reardan et al, 1985; Chang et al, 2002; Boerman et al, 2003; Sharkey et al, 2005).

In this first-in-man phase I study, we investigated pretargeting with the bsMAb, TF2, for targeting CRC. TF2 is a humanised triFab molecule (Rossi et al, 2006), consisting of two anti-CEACAM5 $\mathrm{Fab}$ fragments and another Fab fragment with affinity for the hapten, histamine-succinyl-glycine (HSG). IMP288 is a hapten peptide that contains two HSG moieties to preserve the affinity enhancement properties for improved uptake and retention (Le Doussal et al, 1989; Karacay et al, 2000), and another moiety capable of stable binding of a radionuclide, in this case 1,4,7, 10-tetraazacyclododecane-1,4,7,10-tetraacetic acid (DOTA) for binding ${ }^{90} \mathrm{Y},{ }^{177} \mathrm{Lu}$, and ${ }^{111} \mathrm{In}$ (Rossi et al, 2006; Goldenberg et al, 2008; Schoffelen et al, 2010a). The rapid and specific targeting of human tumour xenografts and the therapeutic potential of pretargeted, radiolabelled hapten-peptides were reported previously (Sharkey et al, 2008; Schoffelen et al, 2010b). The primary goals of this trial were to evaluate several pretargeting conditions and to assess the safety of pretargeting with TF2 and ${ }^{177} \mathrm{Lu}$-labelled IMP288 in patients with metastatic CRC for whom no standard treatment was available.

\section{METHODS}

Patient eligibility. Patients $\geqslant 18$ years of age with progressive metastatic CRC for whom no standard treatment was available were enrolled. Eligibility criteria included Eastern Cooperative Oncology Group (ECOG) performance status $\leqslant 1$, no previous therapies within 4 weeks (bevacizumab within 8 weeks), and adequate haematopoiesis (absolute neutrophil count $\geqslant 1.5 \times 10^{9}$ per litre; platelets $\geqslant 150 \times 10^{9}$ per litre without transfusion during the previous month; haemoglobin $\geqslant 5.6 \mathrm{mmoll}^{-1}$ ), and with acceptable hepatic (total bilirubin $\leqslant 2 \times$ upper limit of normal (ULN), aspartate transaminase (AST)/alanine transaminase (ALT) $\leqslant 3 \times \mathrm{ULN}$ ) and renal function (serum creatinine $\leqslant 2 \times \mathrm{ULN}$, Cockcroft clearance $\left.>50 \mathrm{ml} \mathrm{min}^{-1}\right)$. Evidence of CEA expression by tissue staining ( $>20 \%$ of the tumour cells CEA positive) or elevated plasma levels was required. Patients with a life expectancy of $<6$ months, known brain metastases, or cardiac disease with New York Heart Association classification of III or IV, were excluded.

The regional ethics review committee (CMO Regio ArnhemNijmegen) approved the study protocol and amendments. Written informed consent was obtained from all patients. The study was registered at ClinicalTrials.gov (NCT00860860; http://www. clinicaltrials.gov/ct2/results?term=NCT00860860).

Study design. Preclinical studies showed successful pretargeting of tumours depends on three factors: the bsMAb dose, the interval between the administration of the bsMAb and the radiolabelled hapten-peptide, and the dose of the hapten peptide (Sharkey et al, 2003a; Schoffelen et al, 2010b). Tumour targeting of the radiolabelled hapten peptide will be affected by: (1) the amount of bsMAb in the tumour, which should be high enough to provide efficient capture of the radiolabelled peptide and (2) the bsMAb concentration in the circulation, which should be low at the time of the radiolabelled hapten peptide administration to prevent extensive complex formation with the bsMAb. Complex formation would increase the circulatory half-life of the radiolabelled hapten peptide and in turn increasing the radiation exposure to normal tissues. Additionally, animal studies showed that the dose of the hapten peptide should be minimised to increase the fraction that targets the tumour (Schoffelen et al, 2010b). For this clinical trial, the IMP288 dose was selected based on the minimum amount required to radiolabel the peptide with $7.4 \mathrm{GBq}{ }^{177} \mathrm{Lu}$ (maximum specific activity $74 \mathrm{MBq} \mu \mathrm{g}^{-1}$, therefore $100 \mu \mathrm{g}(68.6 \mathrm{nmol})$ was required). Animal data also had indicated the molar ratio between the TF2 and IMP288 dose should be at least $10: 1$, and therefore our goal was to adjust the bsMAb and peptide to achieve this minimum ratio (Schoffelen et al, 2010b).

To evaluate these interdependent factors relevant for tumour targeting, we studied four dose schedules in cohorts of five patients (Table 1). First, the effect of the interval between bsMAb and hapten peptide was studied: cohort 1 received TF2 (75 mg; $477 \mathrm{nmol})$ and IMP288 (100 $\mu \mathrm{g} ; 68.6 \mathrm{nmol})$ with a 5-day interval, while cohort 2 received the same doses with a 1-day interval. The 5-day interval was based on preclinical studies that showed a substantially slower blood clearance rate for TF2 in rabbits than in mice, and thus for the first-in-man experience, the longer interval was chosen for the first cohort (Sharkey et al, 2010). Once the rapid clearance rate of TF2 was determined, it was apparent that a 1-day spacing would be suitable, and thus all other cohorts used this interval. The bsMAb dose also was examined, with cohort 3 receiving a higher bsMAb dose (150 mg TF2, 1-day interval, $100 \mu \mathrm{g}$ IMP288), while all other cohorts received $75 \mathrm{mg}$ of TF2. Finally, with the availability of ${ }^{177} \mathrm{Lu}$ at a higher specific activity, in cohort 4 , it was possible to test a lower IMP288 dose (75 mg TF2, $25 \mu \mathrm{g}$ IMP288, 1-day interval), with $25 \mu \mathrm{g}$ being the minimum amount of IMP288 required to prepare the maximum amount of ${ }^{177} \mathrm{Lu}$ activity $(7.4 \mathrm{GBq})$ per treatment.

Patients first underwent a diagnostic imaging cycle with TF2 and ${ }^{111}$ In-labelled IMP288. If tumour targeting of the radiolabelled peptide was observed, then patients received a therapeutic cycle of TF2 and ${ }^{177} \mathrm{Lu}-\mathrm{IMP} 288$ the following week (Figure 1). By quantitatively analysing the ${ }^{111}$ In-IMP288 scintigraphic images and pharmacokinetics, the radiation dose to the kidney and bone marrow was estimated. The amount of ${ }^{177}$ Lu-IMP288 activity to be given as the therapeutic dose was set on an individual patient basis, designed to deliver no $>1.25$ Gy to the bone marrow or $15 \mathrm{~Gy}$ to the kidneys. This total dose was split into four equally divided treatment cycles, with the intent to administer each cycle every 8 weeks, since the nadir for directly radiolabelled IgG therapy usually occurs within 5-6 weeks. The maximum allowed dose per cycle was set initially for cohort 1 at $3.7 \mathrm{GBq}$, but was increased to 7.4 GBq for all subsequent cycles.

Preparation and administration of investigational drugs. The clinical-grade bsMAb, TF2, and the IMP288 hapten peptide were

Table 1. Study design
\begin{tabular}{|l|c|c|c|}
\hline Cohort $(\mathbf{n}=\mathbf{5})$ & TF2 $(\mathbf{m g})$ & Interval (days) & IMP288 $(\boldsymbol{\mu g})$ \\
\hline 1 & 75 & 5 & 100 \\
\hline 2 & 75 & 1 & 100 \\
\hline 3 & 150 & 1 & 100 \\
\hline 4 & 75 & 1 & 25 \\
\hline
\end{tabular}




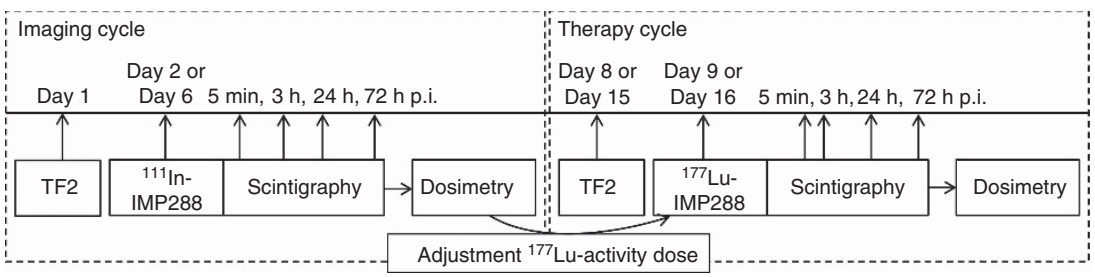

Figure 1. Treatment schedule. Patients received an imaging cycle with TF2 and ${ }^{111} \mathrm{In}-\mathrm{IMP} 288$ to determine the pharmacokinetics and radiation dose to the red bone marrow and kidneys. A safe, cumulative ${ }^{177} \mathrm{Lu}$-activity dose was estimated, and one-fourth of this amount was administered in the first therapy cycle.

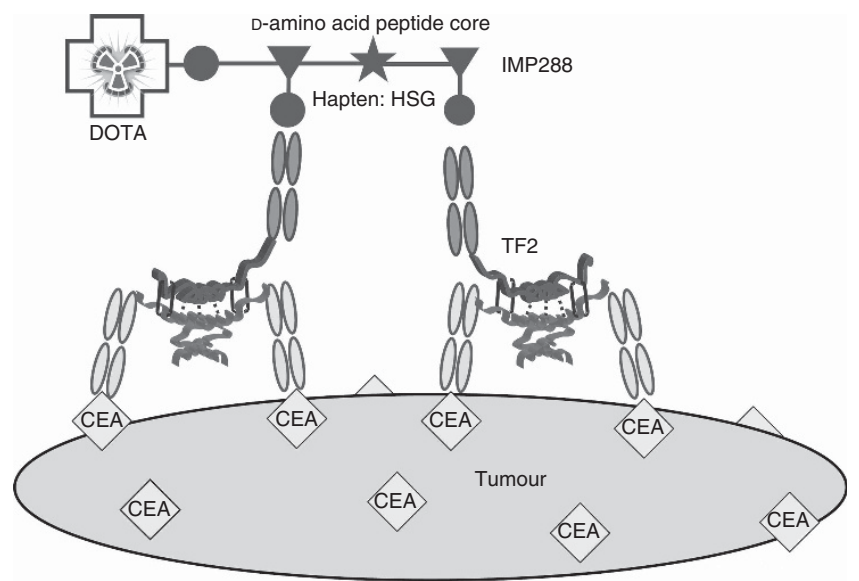

Figure 2. Schematic representation of the pretargeting agents. The trivalent bispecific antibody construct, TF2, binds divalently to CEACAM5, the tumour-associated antigen that is overexpressed on the cell surface of colorectal tumour cells. After the bsMAb has localised the tumour and cleared from the blood, a radiolabelled divalent peptide is given, substituted with the hapten, histamine-succinylglycine (HSG). This is rapidly targeted to the tumours and bound by high affinity to the anti-HSG Fab fragment of the bsMAb. Due to its bivalency, it has the ability to crosslink the bsMAbs at the tumour surface, forming a stable complex. The peptide is conjugated with the chelator, DOTA that can be labelled with a variety of radionuclides.

provided by Immunomedics (Morris Plains, NJ, USA) (Figure 2). The binding characteristics of the bispecific antibody, TF2, were described previously (Rossi et al, 2006). IMP288 (molecular weight $1456 \mathrm{Da}$ ) was synthesised as described by McBride et al (2006). TF2 was diluted in $60 \mathrm{ml} 0.9 \% \mathrm{w} / \mathrm{v} \mathrm{NaCl}$, and administered by i.v. infusion over a period of $2 \mathrm{~h}$. Starting from the second patient of cohort 2, all patients received a prophylactic dose of the antihistamine, clemastine $(2 \mathrm{mg}$ ) i.v. $15 \mathrm{~min}$ before start of the second TF2 infusion. Dexamethasone (10 mg i.v.) was added subsequently as an additional prophylactic medication before the second TF2 infusion, starting from the last patient of cohort 3.

IMP288 was labelled as described previously (Schoffelen et al, $2010 \mathrm{~b}$ ), either with $185 \mathrm{MBq}{ }^{111} \mathrm{In}$, a gamma-emitter for pretherapy imaging study or with $3.7-7.4 \mathrm{GBq}{ }^{177} \mathrm{Lu}$, a therapeutic beta-emitter that also has a gamma emission capable of being imaged. The radiochemical purity was $>95 \%$ for all preparations. ${ }^{111} \mathrm{In}$ - and ${ }^{177} \mathrm{Lu}$-IMP288 were diluted in 10 or $20 \mathrm{ml}$ of $0.9 \% \mathrm{NaCl}$, respectively, and were administered by an intravenous 2-min bolus injection.

Scintigraphic assessment and analysis. Anterior and posterior whole-body planar scintigraphic images (Siemens Ecam, Hoffmann Estates, IL, USA) were acquired at $5 \mathrm{~min}, 3 \mathrm{~h}, 24 \mathrm{~h}$, and $72 \mathrm{~h}$ after injection of IMP288. SPECT scans were also taken of regions where $\geqslant 1$ tumours were in the field of view.
Radioactivity concentrations were determined by drawing regions of interest at tumours and muscle in the psoas region in the SPECTs that were acquired $24 \mathrm{~h}$ after injection of ${ }^{111}$ In-IMP288. Tumour-to-normal tissue ratios were calculated.

Patient evaluation and follow-up. Toxicity assessment, haematology, clinical biochemistry, physical examination, and ECOG performance status were performed at baseline and weekly during follow-up, up to 8 weeks after therapy. Urinary analysis was performed weekly to monitor proteinuria. Patients were monitored closely during and up to $5 \mathrm{~h}$ after the TF2 infusions and IMP288 injections. Toxicity was evaluated according to the NCI Common Terminology Criteria for Adverse Events v3.0 (NCI-CTCAE).

To evaluate tumour response, a baseline FDG-PET/CT (contrast-enhanced) scan was performed within 2 weeks before therapy, and 8 weeks after the ${ }^{177}$ Lu-IMP288 injection. Responses were evaluated according to the Response Evaluation Criteria in Solid Tumours (RECIST) (Eisenhauer et al, 2009).

Pharmacokinetics. TF2 concentrations in serum samples were determined using a sandwich enzyme-linked immunosorbent assay (ELISA), using plates coated with an HSG-conjugated peptide coupled to bovine serum albumin. After incubating with dilutions of the patient's serum samples, binding was revealed with an antiidiotype antibody directed against the humanised anti-CEACAM5 portion of TF2 (Sharkey et al, 2010).

${ }^{111}$ In- and ${ }^{177} \mathrm{Lu}$-IMP288 pharmacokinetics were determined by measuring the radioactivity in blood samples in a gamma counter along with standards prepared from the injected products for determination of the percentage of the injected dose per gram tissue $\left(\% \mathrm{ID} \mathrm{g}^{-1}\right)$.

Human-anti-human antibody measurements. Human-anti-human antibody (HAHA) was determined before each TF2 infusion and up to 8 weeks after the last TF2 infusion. The HAHA directed against TF2 was measured with a sandwich ELISA. Serial dilution of patient serum was incubated in TF2-coated wells. Wells were probed with a TF2-horseradish peroxidase conjugate, and binding was revealed using o-phenylenediamine dihydrochlorides. Concentration of anti-TF2 responses $\left(\mathrm{ng} \mathrm{ml}^{-1}\right)$ was based on a standard curve using a rat anti-idiotype antibody specific to hMN-14, WI2 (Losman et al, 1994). The detection limit of the assay is $50 \mathrm{ng} \mathrm{ml}^{-1}$, and therefore a positive HAHA was arbitrarily set as any value above this level.

\section{RESULTS}

Twenty-one patients were enrolled in the study between July 2009 and July 2011. Baseline characteristics of the patients who received TF2 ${ }^{111} \mathrm{In} /{ }^{177} \mathrm{Lu}-\mathrm{IMP} 288$ cycles are reported in Table 2 . One patient (patient 1) was withdrawn from the study before the ${ }^{177} \mathrm{Lu}-$ IMP288 treatment. He experienced a hypoxia grade 2 during the second TF2 infusion; and therefore, the infusion was discontinued and the patient was withdrawn. 


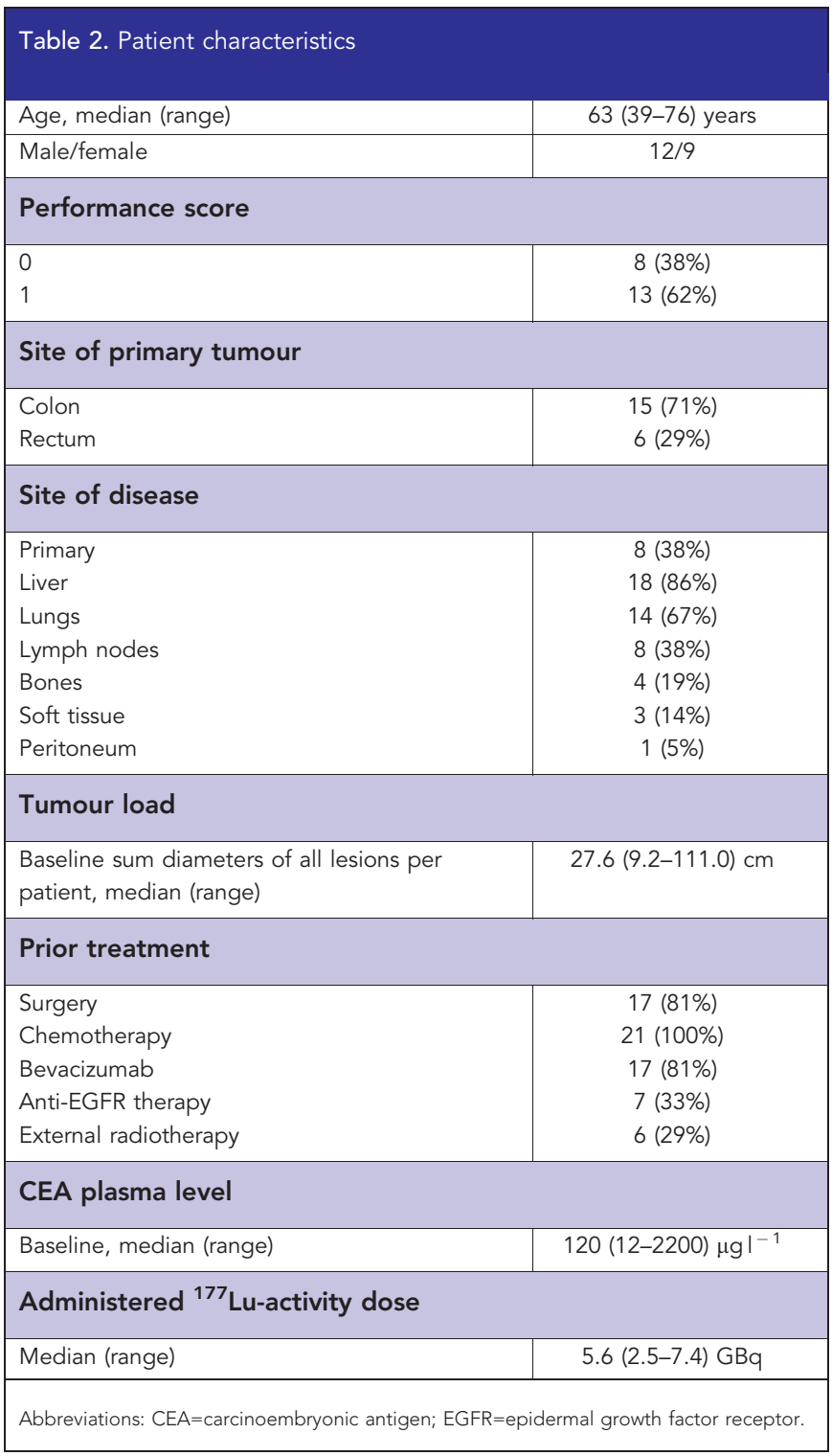

Most patients had large tumour loads, with many large lesions in multiple organs. The low estimated red marrow doses allowed administration of the maximum ${ }^{177} \mathrm{Lu}$-IMP288 dose in a number of patients (e.g., 4, 2, and 3 patients in cohort 2 through 4, respectively, received $7.4 \mathrm{GBq}$ ). The other patients in cohorts $2-4$ received ${ }^{177} \mathrm{Lu}$-activity doses ranging from 2.5 to $6.2 \mathrm{GBq}$ to avoid exceeding one-fourth of the maximum cumulative red marrow absorbed dose $(1.25 \mathrm{~Gy})$. The renal dose threshold was never an issue for assignment of the therapeutic dose.

Pharmacokinetics. Measurements of ELISA indicated that TF2 cleared rapidly from the blood, with $86 \%$ of the ID eliminated at $6 \mathrm{~h}$ after completion of the infusion, and 99\% ID after $24 \mathrm{~h}$ in all cohorts. TF2 clearance was not related to the CEA plasma level at the time of infusion (data not shown). TF2 concentrations in the blood increased proportionally with the dose administered (Figure 3a).

Radiolabelled IMP288 cleared the fastest in cohort 1, where the initial interval was 5 days (Figure 3b). Because TF2 cleared quickly, the interval was then adjusted to 1 day for cohort 2. In this cohort, the clearance rate of IMP288 slowed, but it was still very rapid. As expected, IMP288 clearance slowed when conditions favoured a higher ratio of moles of TF2 in the blood to the moles of IMP288 injected. For example, IMP288 concentrations were higher in cohort 3 that received $150 \mathrm{mg}$ than in patients of cohort 2 that
A
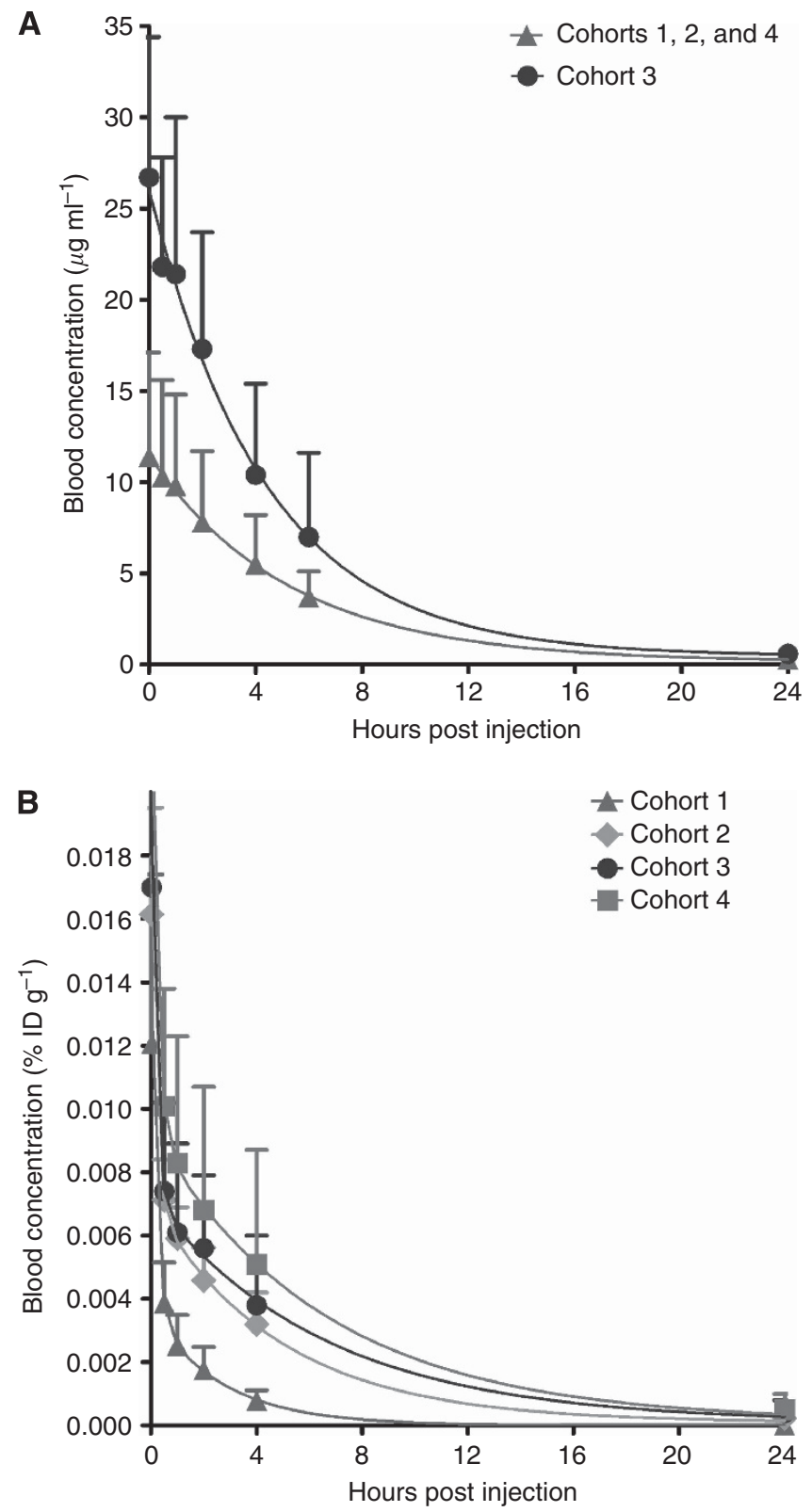

Figure 3. Pharmacokinetics. (A) Serum clearance of TF2 determined by ELISA in cohorts 1, 2, and 4 that received $75 \mathrm{mg}$ of TF2, and in cohort 3, $150 \mathrm{mg}$ (mean \pm standard deviation; $N=5$ per cohort). TF2 cleared rapidly from the serum, with cohort 3 having twice as high serum concentrations. (B) ${ }^{111}$ In-IMP288 blood clearance per cohort (mean \pm standard deviation; $N=5$ per cohort). In all cohorts, $>98 \%$ ID was cleared at $24 \mathrm{~h}$ p.i., although peptide blood clearance was somewhat delayed by shortening the interval between bsMAb and peptide administration, and to a lesser extent due to a higher antibody and a lower peptide doses.

received $75 \mathrm{mg}$ (Figure $3 \mathrm{~b}$ ). Overall, most of the administered radioactivity had cleared from the blood at $24 \mathrm{~h}$ post injection in all cohorts $(100 \%, 99 \%, 98 \%$, and $98 \%$ ID, cohorts $1-4$, respectively).

Scintigraphic imaging analysis. In all patients, the ${ }^{111}$ In-IMP288 images showed clear and selective targeting of known tumour lesions; and thus, all patients were eligible to receive a therapeutic TF2 $/{ }^{177}$ Lu-IMP288 cycle. Primary tumours, as well as metastases in the lungs, liver, lymph nodes, and soft tissue, were visualised as early as $1 \mathrm{~h}$ after injection. Representative images of patient 21 in cohort 4 are shown in Figure 4. 
The pretherapy ${ }^{111}$ In scans and the posttherapy ${ }^{177} \mathrm{Lu}$ scans were congruent, with a somewhat stronger signal in the ${ }^{177} \mathrm{Lu}$ scans due to higher levels of activity given. After 1 day, most activity had cleared from the normal tissues, with very limited retention in the kidneys, resulting in high tumour-to-normal tissue ratios ( $>20: 1$ at $24 \mathrm{~h}$ ) in all cohorts (Table 3). Shortening the interval between the bsMAb and peptide administration in cohort 2 resulted in significantly higher absolute activity concentrations in all tumours compared with cohort 1 $(P=0.0079)$ and in higher tumour-to-normal tissue ratios $(P=0.046)$. Furthermore, all patients in cohort 4 with liver metastases $(n=3)$ appeared to have higher tumour activity concentrations $(6.3,9.7$, and $23.6 \%$ ID per $\mathrm{kg}$ ) and tumourto-normal tissue ratios $(33,38$, and 84$)$ than the patients in cohort 2 with liver metastases $(n=4)$ (tumour activity concentrations: $3.2,4.7,5.4$, and $5.7 \%$ ID per kg, and tumour-tonormal tissue ratios: $20,24,27$, and 29 at $24 \mathrm{~h}$ p.i.), suggesting improved tumour targeting at the lower peptide dose (25 vs $100 \mu \mathrm{g})$.

Overall, the combined effect of shortening the interval and reducing the peptide dose resulted in significantly higher tumour activity concentrations and tumour-to-normal tissue ratios (cohort 1 vs cohort $4, P=0.0079$ and $P=0.035$, respectively).

Efficacy, safety, and tolerability. According to RECIST based on the FDG-PET/contrast-enhanced CT scans before therapy and 8 weeks after therapy, all patients showed progressive disease 8 weeks after the first therapy cycle with TF2 and ${ }^{177} \mathrm{Lu}-\mathrm{IMP} 288$; and therefore, none of the patients were eligible for a second treatment cycle. Thus, only the safety and tolerability of one of the four planned treatment cycles can be reported.
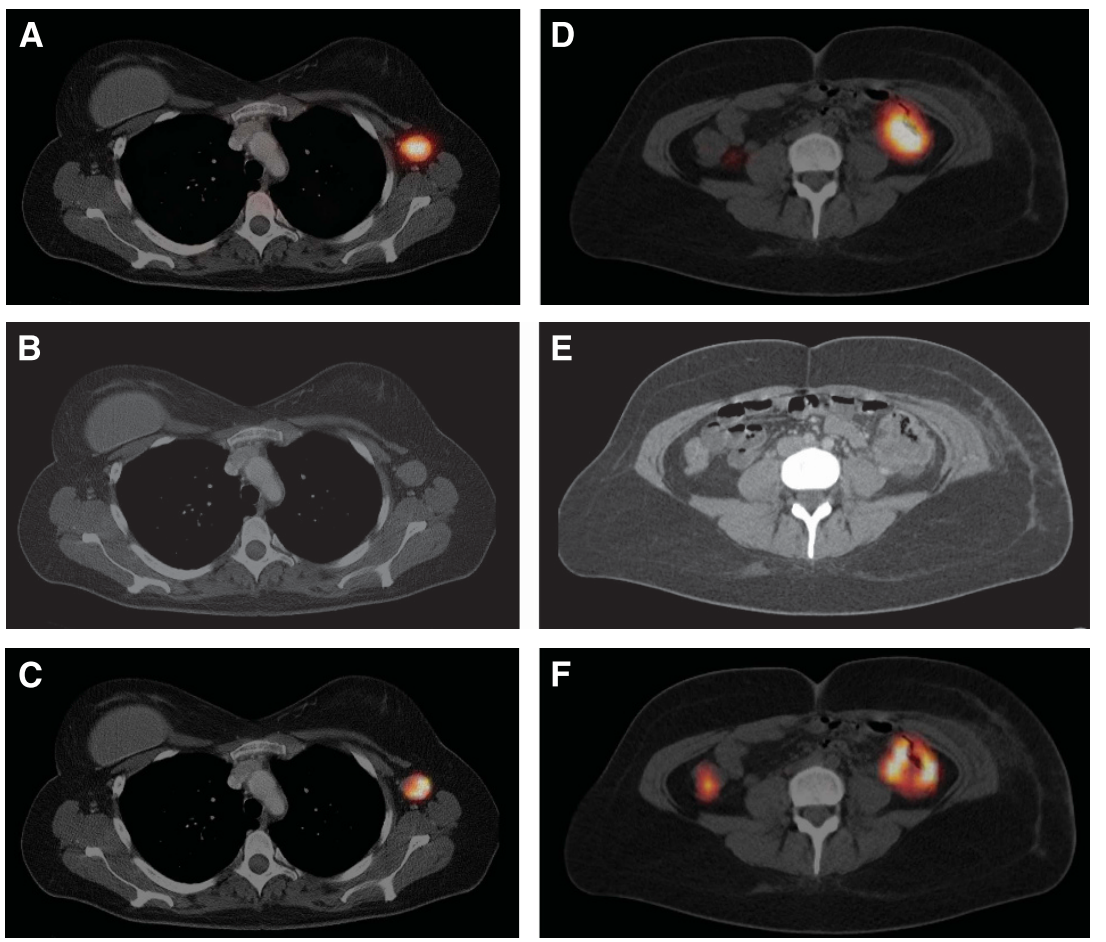

Figure 4. Scintigraphic images. The SPECT/CT image (A), acquired $24 \mathrm{~h}$ after injection of ${ }^{111}$ In-IMP288 (185 MBq, $\left.25 \mu \mathrm{g}\right)$, pretargeted with $75 \mathrm{mg}$ TF2 (1-day interval), in a 38-year-old patient (cohort 4), shows very clear tumour targeting of an axillary lymph-node metastasis, with very low concentrations of radioactivity in normal tissues. This patient had a CEA level of $17 \mu \mathrm{gl}^{-1}$ and the concentration of ${ }^{111}$ In-IMP288 in the tumour was $6.3 \% \mathrm{ID} \mathrm{kg}^{-1}$, with a tumour-to-normal tissue ratio of 33. Corresponding contrast-enhanced CT scan and a fused FDG-PET/CT scan are shown (B and $\mathbf{C}$, respectively). The primary colon tumour $(50 \mathrm{~cm}$ ab ano) also shows highly specific tumour targeting in the SPECT image (D), confirmed by the CT scan and FDG-PET/CT (E and F, respectively), with non-specific FDG uptake in the ascending colon.

Table 3. Tumour targeting

bsMAb dose/interval/peptide dose

\begin{tabular}{|c|c|c|c|c|}
\hline & \multicolumn{4}{|c|}{ bsMAb dose/interval/peptide dose } \\
\hline & $\begin{array}{c}75 \mathrm{mg} / 5 \text { days } / 100 \mu \mathrm{g} \\
\text { Cohort } 1\end{array}$ & $\begin{array}{c}75 \mathrm{mg} / 1 \text { day } / 100 \mu \mathrm{g} \\
\text { Cohort } 2\end{array}$ & $\begin{array}{c}150 \mathrm{mg} / 1 \text { day } / 100 \mu \mathrm{g} \\
\text { Cohort } 3\end{array}$ & $\begin{array}{c}75 \mathrm{mg} / 1 \text { day } / 25 \mu \mathrm{g} \\
\text { Cohort } 4\end{array}$ \\
\hline \multicolumn{5}{|c|}{ Activity concentration (\%ID kg ${ }^{-1}$, mean (range)) } \\
\hline Tumour & $1.4(0.8-2.0)$ & $4.4(2.7-5.7)$ & $5.9(3.1-10.4)$ & $9.4(2.2-23.6)$ \\
\hline Normal tissue & $0.068(0.042-0.093)$ & $0.18(0.12-0.24)$ & $0.19(0.08-0.31)$ & $0.21(0.10-0.28)$ \\
\hline Tumour-to-normal tissue ratio (mean (range)) & $20(17-22)$ & $24(20-29)$ & $32(22-43)$ & $40(21-84)$ \\
\hline
\end{tabular}


Toxicity was limited in most patients, with no apparent differences between cohorts (Table 4). The majority of the patients with liver metastases had liver enzyme elevations before drug administrations (e.g., 43\% had grades 3-4 GGT elevation at baseline). In many patients, GGT increased during the trial, which was deemed to be disease related, since all patients had progression of liver metastases, as seen on the FDG-PET/CT scans.

Seven patients (33\%) experienced a mild grade 2 infusion reaction during onset of their second TF2 infusion. They experienced flushes, dyspnoea, chest pain, back pain, or coughing. They did not have cutaneous, cardiovascular, or gastrointestinal signs or symptoms. All reactions were easily controlled by interrupting the infusion, and with intravenous administration of clemastine $(2 \mathrm{mg})$ and dexamethasone $(10 \mathrm{mg})$. Except for patient 1 , with grade 2 hypoxia, the infusion was restarted in all patients at a slower infusion rate for $15 \mathrm{~min}$, and could be completed at the planned infusion rate without any recurrence of symptoms. After three infusion reactions (from patient 8 ), prophylactic intravenous clemastine $(2 \mathrm{mg}$ ) was added before the patients' second TF2 infusion. After patient 15, prophylactic intravenous dexamethasone $(10 \mathrm{mg})$ was added. With this regimen, infusion reactions occurred in 2 out of 5 patients, but the TF2 infusions could be completed as described above.

Following the single therapy cycle, bone marrow toxicity was mild in most patients (grades $1-2$ in $30 \%$ of patients). More severe haematological toxicity (grades 3-4 thrombocytopaenia, and grade 3 lymphopaenia) occurred in two patients (10\%; 1 in cohort 2 and 1 in cohort 3$)$, with the nadir $5-6$ weeks after ${ }^{177} \mathrm{Lu}$ administration. Recovery was rapid, returning to grade $\leqslant 1$ level at $7-8$ weeks after therapy. None of these patients had complications or needed intervention. None of the patients showed signs or symptoms of renal toxicity.

One patient (in cohort 3) was admitted to the hospital due to severe dyspnoea 4 days after the administration of ${ }^{177} \mathrm{Lu}-\mathrm{IMP} 288$. High-resolution CT of the chest was unremarkable, lung function tests were normal and blood or sputum cultures, as well as viral serology, remained negative. The event was reported as probably related to the drug administrations, either TF2 or ${ }^{177}$ Lu-IMP288, and thus recorded as a Suspected Unexpected Serious Adverse Reaction (SUSAR). The patient's dyspnoea decreased, but remained at a lower level, which might have been related to rapid progression of disease, since this patient had progressive lung metastases.

Human antibodies against $\mathrm{TF} 2>50 \mathrm{ng} \mathrm{ml}^{-1}$ were detected in 11 of 21 patients, starting 1 week after the second TF2 infusion, and gradually increasing in the follow-up period of 8 weeks, indicating that the humanised trivalent bsMAb TF2 was immunogenic in $\sim 50 \%$ of the patients upon repeated injection. Titers varied widely among patients (mean $386 \mathrm{ng} \mathrm{ml}^{-1}$, range 53-800 $\mathrm{ng} \mathrm{ml}^{-1}$ ).

\begin{tabular}{|c|c|c|c|c|c|}
\hline & & \multicolumn{3}{|c|}{ Grade } & \multirow[b]{2}{*}{ Total of grades 2-4 } \\
\hline & & 2 & 3 & 4 & \\
\hline Category & Adverse event & \multicolumn{3}{|c|}{ (No. of patients) } & (\%) \\
\hline Blood/bone marrow & \begin{tabular}{|l|} 
Platelets \\
Lymphocytopaenia \\
Haemoglobin
\end{tabular} & $\begin{array}{l}1 \\
1 \\
2\end{array}$ & $\begin{array}{l}1 \\
2 \\
1\end{array}$ & 1 & $\begin{array}{l}14 \\
14 \\
19\end{array}$ \\
\hline Syndromes & Acute infusion-related reaction & 7 & & & 33 \\
\hline Constitutional symptoms & \begin{tabular}{|l|} 
Fatigue \\
Fever \\
Sweating
\end{tabular} & $\begin{array}{l}4 \\
1 \\
1\end{array}$ & & & $\begin{array}{r}19 \\
5 \\
5\end{array}$ \\
\hline Pulmonary & Dyspnoea & 1 & 1 & & 10 \\
\hline Gastrointestinal & $\begin{array}{l}\text { Nausea } \\
\text { Anorexia } \\
\text { Diarrhea }\end{array}$ & $\begin{array}{l}1 \\
4\end{array}$ & 2 & & $\begin{array}{r}5 \\
19 \\
10\end{array}$ \\
\hline Pain & $\begin{array}{l}\text { Abdomen } \\
\text { Tumour }\end{array}$ & $\begin{array}{l}3 \\
1\end{array}$ & 1 & & $\begin{array}{r}19 \\
5\end{array}$ \\
\hline Neurology & $\begin{array}{l}\text { Somnolence } \\
\text { Pyramidal tract dysfunction }\end{array}$ & $\begin{array}{l}2 \\
1\end{array}$ & & & $\begin{array}{r}10 \\
5\end{array}$ \\
\hline Infection & Biliary tree ${ }^{\mathbf{b}}$ & & 1 & & 5 \\
\hline Musculoskeletal & Arthritis (non-septic) & 1 & & & 5 \\
\hline Renal & Urinary frequency & 1 & & & 5 \\
\hline Metabolic/laboratory & $\begin{array}{l}\text { AST } \\
\text { ALT } \\
\text { Bilirubin } \\
\text { Albumin, serum low } \\
\text { Alkaline phosphatase } \\
\text { GGT }\end{array}$ & $\begin{array}{l}4 \\
2 \\
1 \\
6 \\
5 \\
4\end{array}$ & $\begin{array}{l}1 \\
1 \\
2 \\
\\
5 \\
7\end{array}$ & 3 & $\begin{array}{l}24 \\
14 \\
14 \\
29 \\
48 \\
67\end{array}$ \\
\hline
\end{tabular}




\section{DISCUSSION}

Pretargeting aims to improve the efficacy of tumour targeting with monoclonal antibodies. Recently, a survival benefit for patients with medullary thyroid carcinoma following treatment with pretargeted RIT with an ${ }^{131} \mathrm{I}$-di-DTPA peptide (1.9-5.5 GBq) was reported (Chatal et al, 2006).

Preclinical studies with the pretargeting system used in this study (Rossi et al, 2006; Goldenberg et al, 2008) have shown that this system can used for PET or SPECT imaging (McBride et al, 2006; Schoffelen et al, 2010a), and for pretargeted RIT (Sharkey et al, 2003b; Schoffelen et al, 2010b). These studies showed that accurate dosing of the bsMAb and the radiolabelled peptide is crucial to obtain optimal tumour targeting (Schoffelen et al, 2010b).

In this first-in-man pretargeting study with TF2 and ${ }^{111} \mathrm{In} /{ }^{177} \mathrm{Lu}$ labelled IMP288, we showed that pretargeting provided rapid and efficient targeting of CEACAM5-expressing tumours with low normal tissue activity levels. The main objective of this study was to evaluate several dosing conditions to assess their effect on biodistribution and tumour targeting. The interval of 5 days that was applied in the first cohort was selected based on blood clearance studies of TF2 in rabbits (Sharkey et al, 2010), but when it became clear that TF2 cleared relatively rapidly in humans, the interval was reduced to 1 day. The blood clearance of TF2 was much faster than that of similarly sized IgG molecules, which could be explained by the fact that TF2 lacks a $\mathrm{C}_{\mathrm{H} 2}$ domain (Chinn et al, 2006). In nude mouse-human tumour xenograft models, an interval of $16-24 \mathrm{~h}$ was optimal (Sharkey et al, 2003a; Schoffelen et al, 2010b). In addition, TF2's peak tumour uptake occurred $\sim 6 \mathrm{~h}$ post injection in these models, decreasing gradually over time, and thus minimising the interval allowed the hapten peptide to be captured when more bsMAb is present in the tumour.

Overall, we found that reducing the interval and the IMP288 dose improved tumour targeting. Higher bsMAb doses also can enhance tumour uptake of the radiolabelled peptide (Schoffelen et al, 2010a, b). We did not observe improved tumour uptake by increasing the TF2 dose four-fold (75-150 mg). We did observe a trend towards increased tumour uptake when the IMP288 dose was lowered from 100 to $25 \mu \mathrm{g}$ using $75 \mathrm{mg}$ of TF2 (e.g., cohort $2 v \mathrm{~s}$ cohort 4). Further modifications might yield additional improvements in tumour uptake while minimising normal tissue uptake; however, such improvements also must be balanced against toxicity. In this study, haematological toxicity appeared to be the most likely dose-limiting effect, since renal doses remained low for all dose levels.

This study demonstrated the safety of pretargeted RIT with TF2 at activity doses of ${ }^{177} \mathrm{Lu}-\mathrm{IMP} 288$ ranging from 2.5 to $7.4 \mathrm{GBq}$. The immune responses, that is, symptomatic infusion reactions and the formation of anti-TF2 antibodies that were observed following the administration of the second TF2 infusion were unexpected, since TF2 is a humanised antibody construct that also lack an Fc moiety. Murine precursors of anti-CEA bsMAb frequently showed immune responses (Kraeber-Bodere et al, 1999; Vuillez et al, 1999), which was reduced by using chimaeric and humanised antibodies. Importantly, the mild, grade 2, acute infusion-related reactions that were observed in one-third of the patients at the second infusion of the humanised bsMAb did not preclude continuation of treatment, except for one patient who had extensive pulmonary metastases. We observed that reducing the infusion rate and the preadministration of prophylactic antihistamines and corticosteroids reduced this adverse event, and this is advised for future studies. The human antibodies against TF2 detected in half of the patients were not present at the time of the second TF2 infusion (i.e., therapy cycle), so TF2's clearance was not affected. No correlation was found between the infusion reactions and the anti-TF2 antibody titers that started to increase within 1 week after the second TF2 infusion. Future studies should consider a more condensed treatment regimen to minimise any impact that HAHA might have on safety and the quality of tumour targeting.

While haematological toxicity of pretargeted RIT was the more apparent event related to the ${ }^{177} \mathrm{Lu}-\mathrm{IMP} 288$ exposure, overall it was minimal, particularly when considering that these patients all had received several lines of chemotherapy and up to $7.4 \mathrm{GBq}$ of ${ }^{177} \mathrm{Lu}-\mathrm{IMP} 288$. Indeed, although the two patients with transient grade $\geqslant 3$ bone marrow toxicity had a somewhat higher bone marrow absorbed dose, the radiation dose to the red marrow was very low, and therefore we suspect that underlying patient-specific factors (age, performance status, effects of prior treatments on haematopoietic stem cell reserve) likely contributed to these toxicities. The dosimetric analysis has been reported previously (Schoffelen et al, 2011), and will be described in more detail elsewhere.

This trial was designed with the intent to administer high levels of ${ }^{177}$ Lu-IMP288 using dosimetry to predict a safe dose. The radiolabelled hapten peptide used in pretargeting can be viewed in a similar manner as radiolabelled peptides that are being used to treat neuroendocrine tumours (Baum and Rosch, 2011), where dosimetry has gained a role in predicting the potential for renal toxicity. In our study, we determined the total therapeutic dose based on a pretherapy imaging study using conservative estimates of the red marrow and renal doses that should not be exceeded. However, for additional safety, this total dose was split into four fractions, allowing sufficient time between each treatment to monitor toxicity, primarily haematological toxicity. Unfortunately our study population had extensive metastatic disease, and thus all patients showed disease progression before additional treatment cycles could be given. This trial was also designed for use with ${ }^{177} \mathrm{Lu}$-IMP288 with an eye to the future application of pretargeted RIT to patients with less bulky disease, since RIT has been shown to be more effective in small-volume disease (Jain, 1990; Liersch et al, 2005). Recent clinical data in patients with advanced pancreatic cancer suggest a fractionated dosing regimen using a ${ }^{90} \mathrm{Y}$-labelled antibody given in combination with low-dose (radiosensitising) gemcitabine can provide disease control and even objective responses (Ocean et al, 2012), giving credibility to pursuing ${ }^{90} \mathrm{Y}$ instead of ${ }^{177} \mathrm{Lu}$ for patients with advanced metastatic disease. Indeed, ${ }^{90} \mathrm{Y}^{\prime}$ 's physical half-life $(64 \mathrm{~h})$ matches the residence time in the tumour better than ${ }^{177}$ Lu-IMP288 (6.7 days).

In conclusion, the results of this phase I clinical study with pretargeted RIT showed rapid and specific tumour targeting of the ${ }^{111} \mathrm{In}$ - or ${ }^{177} \mathrm{Lu}$-hapten peptide IMP288 following pretargeting with the bsMAb TF2. Tumour targeting improved by shortening the interval between the bsMAb and peptide administration, and by lowering the peptide dose. The procedure is safe, and infusion reactions are transient and manageable with appropriate medication and lowering the infusion rate. Further studies will be needed to determine whether improvements in targeting can be obtained by additional adjustments to the pretargeting conditions, as well as revising the protocol design to allow full treatment to be given over a shorter duration.

ACKNOWLEDGEMENTS

This study was supported by Dutch Cancer Society grant no KUN 2008-4038 and NIH grant 1 R43 EB003751.

\section{CONFLICT OF INTEREST}

WJ McBride, DM Goldenberg, and EA Rossi are employed by or have a financial interest in Immunomedics, Inc. 


\section{REFERENCES}

Amado RG, Wolf M, Peeters M, Van Cutsem E, Siena S, Freeman DJ, Juan T, Sikorski R, Suggs S, Radinsky R, Patterson SD, Chang DD (2008) Wild-type KRAS is required for panitumumab efficacy in patients with metastatic colorectal cancer. J Clin Oncol 26(10): 1626-1634.

Baum RP, Rosch F (2011) 1 World Congress on Ga-68 and Peptide Receptor Radionuclide Therapy (PRRNT), June 23-26, 2011, Zentralklinik Bad Berka, Germany. World J Nucl Med 10(1): 1-2.

Boerman OC, van Schaijk FG, Oyen WJ, Corstens FH (2003) Pretargeted radioimmunotherapy of cancer: progress step by step. J Nucl Med 44(3): 400-411.

Bokemeyer C, Bondarenko I, Makhson A, Hartmann JT, Aparicio J, de Braud F, Donea S, Ludwig H, Schuch G, Stroh C, Loos AH, Zubel A, Koralewski P (2009) Fluorouracil, leucovorin, and oxaliplatin with and without cetuximab in the first-line treatment of metastatic colorectal cancer. J Clin Oncol 27(5): 663-671.

Chang CH, Sharkey RM, Rossi EA, Karacay H, McBride W, Hansen HJ, Chatal JF, Barbet J, Goldenberg DM (2002) Molecular advances in pretargeting radioimunotherapy with bispecific antibodies. Mol Cancer Ther 1(7): 553-563.

Chatal JF, Campion L, Kraeber-Bodere F, Bardet S, Vuillez JP, Charbonnel B, Rohmer V, Chang CH, Sharkey RM, Goldenberg DM, Barbet J (2006) Survival improvement in patients with medullary thyroid carcinoma who undergo pretargeted anti-carcinoembryonic-antigen radioimmunotherapy: a collaborative study with the French Endocrine Tumor Group. J Clin Oncol 24(11): 1705-1711.

Chinn PC, Morena RA, Santoro DA, Kazules T, Kashmiri SV, Schlom J, Hanna N, Braslawsky G (2006) Pharmacokinetics and tumor localization of (111)in-labeled HuCC49DeltaC(H)2 in BALB/c mice and athymic murine colon carcinoma xenograft. Cancer Biother Radiopharm 21(2): 106-116.

Eisenhauer EA, Therasse P, Bogaerts J, Schwartz LH, Sargent D, Ford R, Dancey J, Arbuck S, Gwyther S, Mooney M, Rubinstein L, Shankar L, Dodd L, Kaplan R, Lacombe D, Verweij J (2009) New response evaluation criteria in solid tumours: revised RECIST guideline (version 1.1). Eur J Cancer 45(2): 228-247.

Giantonio BJ, Catalano PJ, Meropol NJ, O'Dwyer PJ, Mitchell EP, Alberts SR, Schwartz MA, Benson 3rd AB (2007) Bevacizumab in combination with oxaliplatin, fluorouracil, and leucovorin (FOLFOX4) for previously treated metastatic colorectal cancer: results from the Eastern Cooperative Oncology Group Study E3200. J Clin Oncol 25(12): 1539-1544.

Goldenberg DM, Rossi EA, Sharkey RM, McBride WJ, Chang CH (2008) Multifunctional antibodies by the Dock-and-Lock method for improved cancer imaging and therapy by pretargeting. J Nucl Med 49(1): 158-163.

Gordon LI, Witzig T, Molina A, Czuczman M, Emmanouilides C, Joyce R, Vo K, Theuer C, Pohlman B, Bartlett N, Wiseman G, Darif M, White C (2004) Yttrium 90-labeled ibritumomab tiuxetan radioimmunotherapy produces high response rates and durable remissions in patients with previously treated B-cell lymphoma. Clin Lymphoma 5(2): 98-101.

Govindan SV, Goldenberg DM (2010) New antibody conjugates in cancer therapy. ScientificWorldJournal 10: 2070-2089.

Hurwitz H, Fehrenbacher L, Novotny W, Cartwright T, Hainsworth J, Heim W, Berlin J, Baron A, Griffing S, Holmgren E, Ferrara N, Fyfe G, Rogers B, Ross R, Kabbinavar F (2004) Bevacizumab plus irinotecan, fluorouracil, and leucovorin for metastatic colorectal cancer. N Engl J Med 350(23): 2335-2342.

Jain RK (1990) Physiological barriers to delivery of monoclonal antibodies and other macromolecules in tumors. Cancer Res 50(3 Suppl): 814s-819s.

Karacay H, McBride WJ, Griffiths GL, Sharkey RM, Barbet J, Hansen HJ, Goldenberg DM (2000) Experimental pretargeting studies of cancer with a humanized anti-CEA x murine anti-[In-DTPA] bispecific antibody construct and a (99m)Tc-/(188)Re-labeled peptide. Bioconjug Chem 11(6): 842-854.

Kraeber-Bodere F, Bardet S, Hoefnagel CA, Vieira MR, Vuillez JP, Murat A, Ferreira TC, Bardies M, Ferrer L, Resche I, Gautherot E, Rouvier E, Barbet J, Chatal JF. (1999) Radioimmunotherapy in medullary thyroid cancer using bispecific antibody and iodine 131-labeled bivalent hapten: preliminary results of a phase I/II clinical trial. Clin Cancer Res 5(10 Suppl): 3190s-3198s.

Le Doussal JM, Martin M, Gautherot E, Delaage M, Barbet J (1989) In vitro and in vivo targeting of radiolabeled monovalent and divalent haptens with dual specificity monoclonal antibody conjugates: enhanced divalent hapten affinity for cell-bound antibody conjugate. J Nucl Med 30(8): 1358-1366.

Liersch T, Meller J, Kulle B, Behr TM, Markus P, Langer C, Ghadimi BM, Wegener WA, Kovacs J, Horak ID, Becker H, Goldenberg DM (2005) Phase II trial of carcinoembryonic antigen radioimmunotherapy with 131I-labetuzumab after salvage resection of colorectal metastases in the liver: five-year safety and efficacy results. J Clin Oncol 23(27): 6763-6770.

Losman MJ, Novick KE, Goldenberg DM, Monestier M (1994) Mimicry of a carcinoembryonic antigen epitope by a rat monoclonal anti-idiotype antibody. Int J Cancer 56(4): 580-584.

McBride WJ, Zanzonico P, Sharkey RM, Noren C, Karacay H, Rossi EA, Losman MJ, Brard PY, Chang CH, Larson SM, Goldenberg DM (2006) Bispecific antibody pretargeting PET (immunoPET) with an 124I-labeled hapten-peptide. J Nucl Med 47(10): 1678-1688.

Ocean AJ, Pennington KL, Guarino MJ, Sheikh A, Bekaii-Saab T, Serafini AN, Lee D, Sung MW, Gulec SA, Goldsmith SJ, Manzone T, Holt M, O’Neil BH, Hall N, Montero AJ, Kauh J, Gold DV, Horne H, Wegener WA, Goldenberg DM (2012) Fractionated radioimmunotherapy with (90) Y-clivatuzumab tetraxetan and low-dose gemcitabine is active in advanced pancreatic cancer: A phase 1 trial. Cancer 118(22): 5497-5506.

Reardan DT, Meares CF, Goodwin DA, McTigue M, David GS, Stone MR, Leung JP, Bartholomew RM, Frincke JM (1985) Antibodies against metal chelates. Nature 316(6025): 265-268.

Rossi EA, Goldenberg DM, Cardillo TM, McBride WJ, Sharkey RM, Chang $\mathrm{CH}$ (2006) Stably tethered multifunctional structures of defined composition made by the dock and lock method for use in cancer targeting. Proc Natl Acad Sci USA 103(18): 6841-6846.

Saltz LB, Clarke S, Diaz-Rubio E, Scheithauer W, Figer A, Wong R, Koski S, Lichinitser M, Yang TS, Rivera F, Couture F, Sirzen F, Cassidy J (2008) Bevacizumab in combination with oxaliplatin-based chemotherapy as first-line therapy in metastatic colorectal cancer: a randomized phase III study. J Clin Oncol 26(12): 2013-2019.

Schoffelen R, Boerman OB, van der Graaf WTA, van Herpen CML, McBride WJ, Chang C-H, Rossi EA, Goldenberg DM, Oyen WJG (2011) Phase I clinical study of the feasibility of pretargeted radioimmunotherapy (PT-RAIT) in patients with colorectal cancer (CRC): first results. J Nucl Med 52(Suppl 1): 358.

Schoffelen R, Sharkey RM, Goldenberg DM, Franssen G, McBride WJ, Rossi EA, Chang CH, Laverman P, Disselhorst JA, Eek A, van der Graaf WT, Oyen WJ, Boerman OC (2010a) Pretargeted immunopositron emission tomography imaging of carcinoembryonic antigenexpressing tumors with a bispecific antibody and a $68 \mathrm{Ga}$ - and $18 \mathrm{~F}$-labeled hapten peptide in mice with human tumor xenografts. Mol Cancer Ther 9(4): 1019-1027.

Schoffelen R, van der Graaf WT, Franssen G, Sharkey RM, Goldenberg DM, McBride WJ, Rossi EA, Eek A, Oyen WJ, Boerman OC (2010b) Pretargeted 177Lu radioimmunotherapy of carcinoembryonic antigenexpressing human colonic tumors in mice. J Nucl Med 51(11): 1780-1787.

Sharkey RM, Cardillo TM, Rossi EA, Chang CH, Karacay H, McBride WJ, Hansen HJ, Horak ID, Goldenberg DM (2005) Signal amplification in molecular imaging by pretargeting a multivalent, bispecific antibody. Nat Med 11(11): 1250-1255.

Sharkey RM, Goldenberg DM (2011) Cancer radioimmunotherapy. Immunotherapy 3(3): 349-370.

Sharkey RM, Karacay H, Litwin S, Rossi EA, McBride WJ, Chang CH, Goldenberg DM (2008) Improved therapeutic results by pretargeted radioimmunotherapy of non-Hodgkin's lymphoma with a new recombinant, trivalent, anti-CD20, bispecific antibody. Cancer Res 68(13): 5282-5290.

Sharkey RM, Karacay H, Richel H, McBride WJ, Rossi EA, Chang K, Yeldell D, Griffiths GL, Hansen HJ, Goldenberg DM (2003a) Optimizing bispecific antibody pretargeting for use in radioimmunotherapy. Clin Cancer Res 9(10 Pt 2): 3897S-3913SS.

Sharkey RM, McBride WJ, Karacay H, Chang K, Griffiths GL, Hansen HJ, Goldenberg DM (2003b) A universal pretargeting system for cancer detection and therapy using bispecific antibody. Cancer Res 63(2): 354-363.

Sharkey RM, Rossi EA, McBride WJ, Chang CH, Goldenberg DM (2010) Recombinant bispecific monoclonal antibodies prepared by the dock-andlock strategy for pretargeted radioimmunotherapy. Semin Nucl Med 40(3): 190-203. 
Tol J, Koopman M, Cats A, Rodenburg CJ, Creemers GJ, Schrama JG, Erdkamp FL, Vos AH, van Groeningen CJ, Sinnige HA, Richel DJ, Voest EE, Dijkstra JR, Vink-Borger ME, Antonini NF, Mol L, van Krieken JH, Dalesio O, Punt CJ (2009) Chemotherapy, bevacizumab, and cetuximab in metastatic colorectal cancer. N Engl J Med 360(6): 563-572.

Van Cutsem E, Kohne CH, Hitre E, Zaluski J, Chang Chien CR, Makhson A, D’Haens G, Pinter T, Lim R, Bodoky G, Roh JK, Folprecht G, Ruff P, Stroh C, Tejpar S, Schlichting M, Nippgen J, Rougier P (2009) Cetuximab and chemotherapy as initial treatment for metastatic colorectal cancer. N Engl J Med 360(14): 1408-1417.

Vuillez JP, Kraeber-Bodere F, Moro D, Bardies M, Douillard JY, Gautherot E, Rouvier E, Barbet J, Garban F, Moreau P, Chatal JF (1999)

Radioimmunotherapy of small cell lung carcinoma with the two-step method using a bispecific anti-carcinoembryonic antigen/antidiethylenetriaminepentaacetic acid (DTPA) antibody and iodine-131 Di-DTPA hapten: results of a phase I/II trial.. Clin Cancer Res 5(10 Suppl): 3259s-3267s.

Wiseman GA, Gordon LI, Multani PS, Witzig TE, Spies S, Bartlett NL, Schilder RJ, Murray JL, Saleh M, Allen RS, Grillo-Lopez AJ, White CA (2002) Ibritumomab tiuxetan radioimmunotherapy for patients with relapsed or refractory non-Hodgkin lymphoma and mild thrombocytopenia: a phase II multicenter trial. Blood 99(12): 4336-4342.

Witzig TE, Flinn IW, Gordon LI, Emmanouilides C, Czuczman MS, Saleh MN, Cripe L, Wiseman G, Olejnik T, Multani PS, White CA (2002a) Treatment with ibritumomab tiuxetan radioimmunotherapy in patients with rituximab-refractory follicular non-Hodgkin's lymphoma. J Clin Oncol 20(15): 3262-3269.

Witzig TE, Gordon LI, Cabanillas F, Czuczman MS, Emmanouilides C, Joyce R, Pohlman BL, Bartlett NL, Wiseman GA, Padre N, Grillo-Lopez AJ, Multani P, White CA (2002b) Randomized controlled trial of yttrium-90-labeled ibritumomab tiuxetan radioimmunotherapy versus rituximab immunotherapy for patients with relapsed or refractory low-grade, follicular, or transformed B-cell non-Hodgkin's lymphoma. J Clin Oncol 20(10): 2453-2463.

This work is published under the standard license to publish agreement. After 12 months the work will become freely available and the license terms will switch to a Creative Commons AttributionNonCommercial-Share Alike 3.0 Unported License. 